\title{
O arranjo arquivístico como escrita: uma reflexão sobre a narrativa em imagens a partir do Fundo Pedro Miranda no Arquivo Público e Histórico de Ribeirão Preto'
}

\author{
Archival arrangement as writing: a view of images as \\ narratives from José Pedro Miranda's fund at the Public \\ and Historic Archive in the City Ribeirão Preto
}

Eduardo Ismael MURGUIA²

Tânia Cristina REGISTRO3

RESUMO

Reflete sobre algumas questões importantes para o arranjo de fotografias em arquivos. Considera-se aqui o arranjo arquivístico um ato de comunicação e, como tal, se estrutura através do enunciado narrativo da vida e obra de José Pedro Miranda, intelectual e historiador que na segunda metade do século XX produziu e acumulou vasta documentação sobre Ribeirão Preto, em especial um número significativo de fotografias. $E$ através deste propõe-se analisar a narrativa circunscrita no âmbito das fotografias coletadas por José Pedro Miranda. Para tanto se discute o estatuto documental da fotografia, destacando que em um ambiente de arquivo a fotografia adquire significado na série além da unidade, e que portanto, os conjuntos fotográficos construídos por José Pedro Miranda tornam-se expressão e materialidade de sua compreensão e produção intelectual. Interpretações sobre a construção de bibliotecas como narrativas são utilizadas como alusão a uma possibilidade de entendimento dos arquivos pessoais.

Palavras-chave: imagem e informação; fotografia; arquivos fotográficos; coleções; arquivo público e histórico de Ribeirão Preto, José Pedro Miranda.

\begin{abstract}
A B S TR A C T
This article addresses some important matters regarding the arrangement of photographs in archives. It considers archiving an act of communication. As such, it is structured around the narrative of the life and work of José Pedro Miranda, a conservative intellectual and historian who produced a great deal of documentation, particularly a significant number of photographs of the city of Ribeirão Preto, in the second half of the Twentieth Century. We shall analyze the photos collected by José Pedro Miranda. Thus, the documental nature of photography is discussed, with an emphasis on the archival environment, where significance exists in a series, as well as in the unit. Interpretations of construction of libraries as narratives are used as a reference to the possibility of understanding personal archives.
\end{abstract}

Key words: image and information; photography; photographic archives; collections; Ribeirão Preto public and historic archive, José Pedro Miranda.

1 Este artigo foi publicado originalmente em português com a seguinte referência: MURGUIA, E.I. O arranjo arquivistico como escrita: uma reflexão sobre a narrativa em imagens a partir do fundo Pedro Miranda no Arquivo Público e Histórico de Ribeirão Preto. Arquivos \& Bibliotecas: a \& b, Lisboa, Portugal, v.16, p.115-134, 2005.

${ }^{2}$ Professor Doutor, Faculdade de Filosofia e Ciências, Departamento de Ciência da Informação, Universidade Estadual Paulista Júlio de Mesquita Filho. Av. Hyginio Muzzi Filho, 737, Campus Universitário, 17525-900, Marília, SP, Brasil. Correspondência para/Correspondence to: E.I. MURGUIA.E-mail:<murguia@marilia.unesp.br>.

${ }^{3}$ Historiadora, Arquivo Público e Histórico de Ribeirão Preto. Rua José da Silva, 915, Jardim Paulista, 14090-040, Ribeirão Preto, SP, Brasil. E-mail: <arquivo@cultura.pmrp.com.br>.

Recebido em 23/8/2005 e aceito para publicação em 23/2/2006.

TransInformação, Campinas, 18(1):71-82, jan./abr., 2006 
I N T R O D U Ç Ã O

Quando falamos do arranjo documental, normalmente a atenção recai sobre os aspectos técnicos, como, por exemplo, as regras que regem o agrupamento de documentos ou os processos descritivos, sobre as normas aceitas internacionalmente facilitadoras do trabalho diário dos profissionais da área.

No entanto, o arranjo também obedece a uma tentativa de ordenamento de objetos no espaço. Esses objetos formam parte de uma cultura material, são entidades físicas que possuem textura, altura, peso, volume, etc. e, portanto, ocupam um lugar específico no espaço. Assim, o arranjo de documentos se caracteriza como uma expressão física, uma maneira pela qual os objetos, integrante de fundos e coleções são colocados num espaço específico, visando sempre a uma relação harmoniosa entre continente/ conteúdo.

A operação física do arranjo requer, muitas vezes, que salas ou prédios sejam construídos para abrigar os documentos; em outros casos, os documentos são adaptados aos edifícios, previamente existentes, nos quais serão guardados. Embora sejam, geralmente, negligenciada ${ }^{4}$ a materialidade e a espacialidade de um acervo são qualidades que integram a sua natureza, apesar de aparecerem como irrelevantes.

Encrostado ao aspecto físico do arranjo, um outro aspecto relacionado ao arranjo de um acervo segundo Camargo e Bellotto (1996, p.1), é a "[...] totalidade dos documentos conservados num arquivo", tem a ver com a questão do seu anseio de organização. Qualquer acúmulo documental, quer seja num ambiente de arquivo ou de uma biblioteca, não é uma ação aleatória; pelo contrário, toda emissão, circulação ou acúmulo de documentos pressupõe, ao menos, uma forma de ordenamento.

Podemos aludir que essa ordem se expressa no caso de um arranjo arquivístico, quer num ambiente de arquivo, quer numa biblioteca ou ainda, num museu, em dois níveis: 1) a determinação pela origem ou gênese; e, 2) o seu tratamento por parte de profissionais, que determinam aquilo que o consulente poderá não somente encontrar, mas também aquilo que poderá desejar.

Portanto, colocamos como tema de discussão, no presente artigo, o arranjo como ordenamento e lugar de tensão entre realidade e desejo, ou entre a arte da palavra e a técnica do ofício, a possibilidade do entendimento do arranjo como uma construção onde os significados e os sentidos são colocados pela disposição física de objetos num espaço determinado.

Para o desenvolvimento desta discussão pretendemos usar não somente como exemplo, mas também como objeto de análise, o fundo José Pedro Miranda, integrante do acervo do Arquivo Público e Histórico de Ribeirão Preto.

O Arquivo Público e Histórico de Ribeirão Preto, instituição criada em 1992, junto à estrutura administrativa da Secretaria da Cultura da Prefeitura Municipal de Ribeirão Preto, tem, sob custódia, documentos de origem pública e privada, relacionados à cidade de Ribeirão Preto. Este acervo organizado tem facilitado a produção de muitos trabalhos científicos; esta documentação contribui também para o desenvolvimento de trabalhos de pesquisa de professores e alunos do ensino fundamental e médio. Além disso, empresas de comunicação locais (TV, rádios, jornais, etc.) recorrem ao acervo do Arquivo em busca de informações históricas sobre a cidade.

Por meio da organização e disponibilidade do acervo para consulta pública, foi construída uma imagem institucional positiva do Arquivo como prestador de serviços de informação, e esse tem sido então o principal elemento da política de acervo desenvolvida pelo Arquivo.

Para responder à demanda por informações, destinadas, sobretudo, à produção de trabalhos acadêmicos, além da confecção de instrumentos de pesquisa $^{5}$, o Arquivo empreendeu uma política de

\footnotetext{
4 Salientamos que não trataremos neste trabalho as questões relacionadas à conservação de documentos, aspecto este de suma importância no âmbito de acervos documentais; o aspecto de negligência quanto à materialidade e espacialidade de acervos documentais tem aqui outras conotações, as quais estão apresentadas adiante.

5 Segundo Camargo e Bellotto (1996, p.45), instrumento de pesquisa refere-se a "[...] obra de referência, publicada ou não, que identifica, localiza, resume ou transcreve, em diferentes graus de amplitudes, fundos, grupos, séries e peças documentais existentes num arquivo permanente, com a finalidade de controle e de acesso ao acervo".
} 
recolhimento de documentos de origem privada, com destaque para os arquivos de famílias e pessoais. Assim, o acervo de José Pedro Miranda, historiador e pesquisador da história de Ribeirão Preto, falecido em 1999, foi incorporado ao Arquivo no ano de 2001.

O recolhimento do acervo de José Pedro Miranda trouxe para o Arquivo enormes desafios, tanto pelo volume de documentos apresentados -, uma vez que se configura como o mais numeroso dos fundos privados, com cerca de vinte mil documentos - como no que se refere à complexidade de problemas para a sua organização, pois se caracteriza como o mais heterogêneo, no que se refere a gêneros ${ }^{6}$ de documentos, no universo do acervo do Arquivo Público e Histórico de Ribeirão Preto.

\section{O FUNDO JOSÉ PEDROMIRANDA}

O fundo José Pedro Miranda é composto por aproximadamente vinte mil documentos de vários gêneros, como audiovisual, iconográfico e textual, e abrange o período de 1870 a 1990. Os documentos que o compõem foram doados ao Arquivo de Ribeirão Preto verbalmente, por José Pedro Miranda, no início de 1999. Após o seu falecimento, em 22 de agosto de 1999, os herdeiros do espólio impuseram a condição de empreender uma verificação prévia de todos os documentos antes de proceder à doação formal ao Arquivo. Assim, somente em fevereiro de 2001 foi formalizada a doação dos documentos ao Arquivo Público e Histórico de Ribeirão Preto mediante a assinatura do termo de doação por Raimundo Nonato, irmão de José Pedro Miranda.

Após o recebimento da totalidade do acervo, iniciou-se o processo de identificação dos documentos, iniciado em 2002 e estendido até 2004.

O exame preliminar revelou que inúmeros documentos são provenientes ou originários de algumas das instituições com as quais José Pedro Miranda estabeleceu alguma relação; dada à abrangência das áreas de interesse e a diversidade de atividades profissionais desenvolvidas por José Pedro Miranda, encontramos integrados a este fundo documentos originários dos Museus Municipais, da Biblioteca Padre Euclides, documentos protocolados da Prefeitura Municipal de Ribeirão Preto, Atas da Academia de Letras e Artes de Ribeirão Preto (ALARP), registros e livros da Cúria Metropolitana, entre outros.

Foram identificados também documentos produzidos por José Pedro Miranda, bem como documentos produzidos e coleções acumuladas por outras personalidades locais, como o pintor Ítalo Naso e os historiadores de Ribeirão Preto Osmani Emboaba e Plínio Travassos dos Santos.

A identificação da massa documental do acervo José Pedro Miranda revelou um outro aspecto surpreendente: a presença de um número significativo de fotografias. Integram este acervo um total de 15.866 imagens, entre ampliações em papel - algumas avulsas (preto \& branco e colorido), outras coladas em álbuns e fichas -, negativos, diapositivos e cartões postais. Desse montante, as fotografias (ampliações em papel) totalizam 9.960. Quanto à origem, detectou-se que as fotografias não foram produzidas por José Pedro Miranda, mas reunidas ao longo de sua vida através de um processo de seleção.

Quanto à temática das fotografias, referem-se principalmente a personagens e paisagens rurais e urbanas de Ribeirão Preto; as datas-limite identificadas abrangem o período de 1892 a 1980.

O acervo de documentos de José Pedro Miranda compreende documentos criados ou acumulados pelo titular e refletem os papéis sociais por ele desempenhados ao longo da sua vida (1930-1999). Este conjunto documental enriquece a compreensão da produção intelectual de José Pedro Miranda sobre a história de Ribeirão Preto, além de refletir as atividades profissionais desenvolvidas por ele, e ainda a sua participação junto a entidades e associações de Ribeirão Preto e região; além disso, configura a atividade de colecionador de objetos relacionados à história de Ribeirão Preto que empreendeu ao longo do tempo.

Todavia, a organização do conjunto de documentos fotográficos que integram o acervo José

\footnotetext{
- Camargo e Bellotto (1996, p.41) definem gênero documental como "[...] configuração que assume um documento de acordo com o sistema de signos utilizados na comunicação de seu conteúdo". Como exemplo citamos documentação audiovisual, documentação iconográfica, documentação textual, etc.
} 
Pedro Miranda, bem como a criação de formas de acesso a estes documentos, de modo a atender um amplo leque de consultas, impôs enormes desafios.

A problemática que envolve a organização de documentos fotográficos, recolhidos junto às instituições de custódia, tem sido alvo de inúmeras discussões e desencadeado uma série de propostas de organização. No âmbito do Arquivo Público e Histórico de Ribeirão Preto, algumas tentativas na aplicação de modelos de organização do acervo de fotografias de José Pedro Miranda obtiveram resultados frustrantes, principalmente no que concerne à recuperação do conteúdo informacional das fotografias diante da estrutura organizativa proposta pela arquivística.

A elaboração de um sistema organizacional de documentos fotográficos, segundo os princípios apresentados pela arquivística, implica no tratamento documental que tem como elementos instrumentais o arranjo e a descrição. No caso desse acervo de fotografias, segundo a lógica da organicidade e da proveniência proposta pela arquivística, a elaboração do arranjo apresenta-se como uma construção de sentidos e significados que tem na personalidade de José Pedro Miranda o principal elemento de influência; o arranjo imprime uma inteligibilidade exclusiva e tributária à sua obra. Por esse motivo, no momento do arranjo, o conteúdo das imagens fotográficas, os autores-fotógrafos, os assuntos ou temas retratados, ou seja, os conteúdos informativos das fotografias configuram-se como elementos secundários.

Dado o papel preponderante da vida e personalidade de José Pedro Miranda para o estabelecimento do arranjo dos documentos que compõem este acervo, apresentamos em seguida um breve perfil biográfico do titular. Posteriormente, então, um aprofundamento da discussão sobre a problemática do arranjo de documentos fotográficos.

\section{José Pedro Miranda, o personagem}

José Pedro Miranda, residente em Ribeirão Preto (SP) desde sua infância, adotou os ideais e a forma de vida da cidade na qual residiu quase que a totalidade de sua vida.

Nasceu em 23 de julho de 1930 na cidade de Livramento (BA); filho de Appio Miranda e Maria da Conceição Miranda. Mudou-se para Ribeirão Preto ainda criança, onde realizou todos os seus estudos, do primário à licenciatura em Estudos Sociais e Letras pela Faculdade de Filosofia, Ciências e Letras Barão de Mauá. Atuou como jornalista profissional e foi ainda escritor, editor, funcionário da Prefeitura Municipal e pesquisador da história de Ribeirão Preto (MIRANDA, 1986).

Desenvolveu as suas atividades profissionais nos seguintes locais: foi Diretor dos Museus Municipais de setembro de 1972 a maio de 1983; em 1992 foi readmitido na Prefeitura Municipal, através de ação judicial, quando passou a ocupar o cargo de Coordenador de Museus Municipais; posteriormente prestou serviços junto ao Arquivo Público e Histórico de Ribeirão Preto, onde foi Coordenador de Pesquisas até o seu desligamento da Prefeitura Municipal em 1998 (MIRANDA, 1999).

Trabalhou nos seguintes jornais de Ribeirão Preto: "O Diário Diário da Manhã" e "A Cidade"; foi também funcionário da empresa Grupo Santa Emília (antiga empresa Diederichsen) e da Cúria Metropolitana (MIRANDA, 1986).

José Pedro Miranda foi ainda membro, sócio e sócio-fundador de inúmeras associações e entidades locais, tais como a Academia de Letras e Artes de Ribeirão Preto; secretário da Sociedade Legião Brasileira de Cultura e Civismo; secretário da Associação Cultural de São Simão; membro fundador do Clube e Associação de Esperanto de Ribeirão Preto; delegado regional e presidente da Academia Brasileira de Esperanto; sócio daAssociação Regional de Preservação de Arquivos Municipais (ARPAM); membro daAssociação Regional de Rádio e Imprensa (ARRI); membro da Juventude Operária Católica (JOC); membro da Sociedade Brasileira de Filatelia, do Instituto Histórico e Geográfico de São Paulo e da Sociedade Brasileira de Numismática (MIRANDA, 1986).

Foi autor e editor de inúmeras publicações: "O Veículo", "Ribeirão Dia e Noite", "Focalizando Municípios", "Revista Vivência", "Folha Circulista", "Civismo e Cultura", "O Barrense, Santelmo", "O Pergaminho", "Roteiro Informativo e Turístico de Ribeirão Preto", "Revista do Consumidor", "Viaje Bem", "Informativo do Shopping Center Rodoviária", "Revista Monográfica de Ribeirão Preto", "Revista de Esperanto", entre outras (MIRANDA, 1986). 
Atuou como historiador e pesquisador de vários temas, principalmente história regional e, especialmente, história de Ribeirão Preto. Sobre este último tema, produziu, entre 1956 e 1980, cerca de quinhentos trabalhos (MIRANDA, 1999). Entre as suas publicações, destacam-se: "Ribeirão Preto de Ontem e de Hoje", de 1976, e "Breve Histórico do Café em Ribeirão Preto", de 1980.

Em novembro de 1998, devido a problemas de saúde, solicitou dispensa da Prefeitura Municipal. Faleceu em Ribeirão Preto no dia 22 de agosto de 1999.

Três aspectos importantes da vida de José Pedro Miranda serão destacados:

Sua intelectualidade: José Pedro Miranda se configura como uma expressão da intelectualidade provinciana das cidades do interior do Estado de São Paulo na segunda metade do século XX. Seu pertencimento a instituições tradicionais e ultrapassadas culturalmente em relação aos movimentos artísticos e intelectuais da Capital do Estado de São Paulo faz dele um intelectual representante dos interesses, muitas vezes arcaicos, das agremiações culturais das cidades interioranas. Misto de interesse natural e sincero, a sua figuração social foi um meio de ascensão numa sociedade de tradição rural fundamentada na produção cafeeira. Ele se apresentava como defensor e legitimador de uma "cultura" pertencente às camadas mais abastadas e conservadoras da cidade;

O funcionário público: este aspecto da vida de José Pedro Miranda é uma conseqüência lógica de alguém dedicado ao trabalho intelectual que precisa sobreviver. Os cargos que ele ocupou foram sempre de confiança e eram outorgados pelas autoridades políticas às quais servia com sua reflexão e pensamento. Essa condição de funcionário público Ihe garantiu o trânsito pelas instâncias e lugares dos quais extrairia os materiais para suas obras;

Seu catolicismo: católico militante, José Pedro Miranda passou momentos de envolvimento próximo com a igreja católica ou com a hierarquia eclesiástica. Participante do movimento católico de jovens operários, não descuidava das suas obrigações de Congregado Mariano, com vínculos estreitos com o clero da cidade. Este fato Ihe permitiu ter acesso aos acervos eclesiásticos.
Esses três aspectos da vida de José Pedro Miranda serão vistos evidenciados na sua obra. Cronista e autor de monografias e tratados, sempre relacionados a aspectos históricos de Ribeirão Preto, a sua produção historiográfica foi sempre fundamentada nos princípios da historiografia positivista do século XIX. Historiador inveterado focalizava a sua atenção

[...] aos túmulos, aos papéis de governos, para as cartas, aos jornais, aos trastes, móveis, utensílios e a tudo que pudesse desvendar os caminhos de retorno a um tempo perdido. José Pedro Miranda constrói, num tempo em que não existiam na cidade as universidades, os museus, os arquivos e as bibliotecas, uma coleção de efemérides, de eventos, para a consecução de esquemas biográficos, livros e opúsculos sobre a história da cidade. (REGISTRO, 2005, p.157).

Conseqüentemente, essa profícua preocupação com as fontes documentais consagradas, leva José Pedro Miranda a executar um "inventário". Ainda, ele vê a si mesmo como o próprio inventário que ele executou; personificou e auto-proclamou "[...] ser o inventário de feitos ribeirão-pretanos, cronista de vidas e acontecimentos". (REGISTRO, 2005, p.156).

Esse papel de inventariante e inventário faz de sua biografia a base para a compreensão e entendimento de um importante elemento da sua obra: o arranjo das suas fontes.

\section{FOTOGRAFIA E TRATAMENTO DOCUMENTAL}

Talvez o principal problema de trabalhar com fotografias em arquivos e bibliotecas se deva a dois fatores: a diversidade das suas técnicas, formatos e suportes para a sua guarda, consecução e tratamento; e o problema do conteúdo da imagem fotográfica. No presente trabalho, iremos nos deter nesta última questão.

A partir da leitura de algumas reflexões propostas por Benjamin (1992), Sontag (1981), Freund (1976) e Barthes (1984), e contrapondo as discussões levantadas por estes autores, delineamos a nossa compreensão sobre a fotografia. Acreditamos se fazer necessário o reconhecimento dos diferentes níveis de realidade contidos nesta forma de registro: 
a realidade denotada na sua superfície e aquela conotada através do processo fotográfico efetivado em um determinado contexto histórico. Igualmente necessária é a sua compreensão como um fragmento ou recorte de determinado aspecto da realidade em um determinado tempo.

A fotografia é crível em relação ao referente; atesta, portanto, a existência de uma realidade; mas ao mesmo tempo a fotografia é sempre interpretativa, porque deriva de uma escolha. Não se configura como um espelho da realidade e não guarda traços de total fidelidade a essa realidade. Na fotografia, a parcialidade é algo que está sempre presente no conteúdo da imagem.

A produção fotográfica envolve, em sua gênese, práticas de manipulação da luz, elementos químicos concentrados a determinada dosagem para determinado resultado, tempo de exposição, granulações do papel, etc. Envolve uma tecnologia, mas o ato de fotografar é uma intervenção sobre a realidade sensível, e aquilo que resulta é um produto híbrido onde há a presença do homem e da máquina. Com a invenção da fotografia inaugura-se o olhar mediado por uma tecnologia.

Sontag (1981, p.141), ao discutir sobre o estatuto da imagem fotográfica, especula que a fotografia se aproxima da linguagem, uma vez que como a linguagem "[...] ela é o meio através do qual as obras de arte (entre outras coisas) são realizadas [...]". Ainda segundo Sontag (1981, p.141),

[...] com a linguagem, podem-se fazer discursos científicos, memorandos burocráticos, cartas de amor, listas de compras, e a Paris de Balzac. Com a fotografia, podem-se fazer retratos para passaportes, fotografias meteorológicas, fotografias pornográficas, raios $\mathrm{X}$, retratos de casamento e a Paris de Atget.

Freund (1976) localiza e dimensiona a fotografia como documento social, estabelecendo as bases para a sua compreensão como testemunho histórico. Aidéia apresentada por Freund (1976) sobre a dimensão documental da fotografia, desencadeia a sua interpretação como informação ou como um instrumento de comunicação, portanto passível de manipulação, que pode ocorrer tanto no processo de produção como na leitura da fotografia.

Benjamin (1992) fornece algumas pistas para a análise da fotografia a partir do acaso que nela cintila. Esta mesma expressão é recuperada por Barthes (1984) ao especular sobre o Punctum, aquilo que punge, ao acaso; sobre a fotografia. Barthes (1984) infere, ainda, alguns elementos ou fatos presentes na fotografia, que indicam ser possível traçar algumas regras ou caminhos para uma leitura fotográfica, de maneira descritiva através do Studium, e de maneira narrativa a partir do Punctum.

Todavia, podemos ir um pouco além, se considerarmos a fotografia sob o prisma de duas dicotomias: conotação/denotação e descrição/ narração; ou, se quisermos, de quatro categorias interpretativas que, por sua vez, articulam-se em dois pares. Pretendemos relacionar essas quatro categorias numa espécie de perspectiva cruzada; entendendo a conotação como narrativa e a denotação como descrição.

A interpretação que advém do reconhecimento dessas categorias se fundamenta na inserção da fotografia como um agente significante, isto é, a sua compreensão como fenômeno de comunicação.

Paralelamente, a interpretação da fotografia à qual estamos nos referindo se manifesta também em dois níveis.

Primeiro, o conteúdo fotográfico unitário. Conforme os apontamentos dos autores apresentados no presente trabalho, enveredamos pela discussão da fotografia como dispositivo imagético individual. Assim, a referencialidade do objeto fotográfico, a subjetividade da construção da fotografia, a relação do sujeito-fotógrafo e o seu objeto (ou objetos fotografados) e quem contempla a fotografia são questões articuladas sempre a partir de uma única fotografia.

Assim, a fotografia da namorada na carteira guardada no bolso do namorado, um retrato de um ente querido no álbum de família e a paisagem capturada na viagem de férias possuem estas características apresentadas, ou seja, são demonstrativas, portanto descritivas; ou, ainda, conotativas, portanto, narrativas; a denotação no sentido apontado por Barthes (1984), quando fala do Studium; e a conotação quando fala do Punctum. Essa dualidade apresentada pelo autor se instala tanto no ato fotográfico como no ato receptivo.

Porém, devemos entender a unidade fotográfica como uma convenção, visto que uma 
fotografia individual descreve ou narra, unica-mente, quando considerada sua composição. Assim, mesmo que sintética, a fotografia pode contar acontecimentos.

O segundo nível de interpretação fotográfica: os conjuntos. Este aspecto se relaciona a lugares e práticas sociais específicos. Há lugares, como os arquivos, as bibliotecas, os museus, onde a fotografia, via arranjo/classi-ficação, encontra um lugar de tratamento específico, isto é, documental. As técnicas nesses lugares passam por uma sorte de acúmulo de práticas profissionais. Seja através da espacialidade institucional, seja pela prática profissional, o tratamento documental, através do arranjo/classificação, passará pelo crivo dos conceitos de fundo e coleção.

Aspecto negligenciado quando se discute o tratamento documental de fotografias. Porém, seja a chamada produção orgânica de documentos assumida pela Arquivologia, seja a acumulação artificial defendida no tratamento biblioteconômico dos documentos, o cerne do problema reside no fato de que as fotografias devam sempre ser consideradas nos seus conjuntos e seqüências, portanto, em séries. No caso dos conjuntos fotográficos, além das mediações temporais, espaciais e culturais, devemos agregar a mediação institucional ou organizacional e a mediação profissional, isto é, as mediações materializadas no arranjo/classificação.

Ainda retomando a idéia apontada anteriormente sobre a fotografia como ato comunicacional, apontamos para a necessidade de considerar esse arranjo/classificação de fotografias em arquivos e bibliotecas como enunciados narrativos.

A lingüística estrutural considera a linguagem como manifestação de dois eixos (SAUSSURE, 1997): um sintagmático ou diacrônico, e um paradigmático ou sincrônico, isto é, a interpretação da fotografia individual como um fenômeno diacrônico e vertical, e os conjuntos fotográficos como fenômenos sincrônicos, isto é, de combinações de significados na horizontalidade da linguagem.

Portanto, arquivos e bibliotecas poderiam considerar esses conjuntos, séries ou seqüências, como enunciados de linguagem, enunciados manifestos não unicamente na guarda de fotografias, mas também na disposição, arranjo/classificação e apresentação.
Assim, a questão de fundo (arranjo) ou coleção (classificação) fica sem importância quando o problema se desloca da assepsia documental para a manipulação dos significados e sentidos enunciados pela imagem fotográfica.

No caso dos documentos fotográficos do acervo de José Pedro Miranda, como resultado do processo de tratamento dos documentos, parte das fotografias passaram a integrar séries e dossiês, que compõem os grupos e subgrupos do fundo José Pedro Miranda; nestes casos as fotografias têm as funções de ilustrar determinadas temáticas, registrar fatos e acontecimentos relativos às atividades profissionais e produção intelectual do titular do fundo. Todavia, a maior parte das fotografias passou a compor uma coleção que foi acumulada por José Pedro Miranda ao longo da sua vida.

O arranjo constitui uma das preocupações constantes da Arquivologia. Segundo Bellotto (1991, p.11), os arquivos permanentes empreendem a custódia definitiva dos documentos, "[...] é a guarda perene e responsabilizada de fundos documentais que, passados pelo crivo da avaliação/prazos de vida tornam-se elementos a preservar, analisar e utilizar na pesquisa histórica". Assim, as atividades dos arquivos permanentes, que incidirão sobre os documentos, são o arranjo e a descrição dos fundos.

Ainda segundo Bellotto (1991, p.85), o arranjo "[...] é o processo de agrupamento dos documentos singulares em unidades significativas e o agrupamento, em relação significativa, de tais unidades entre si". A operação do arranjo consiste na ordenação dos conjuntos documentais, obedecendo aos critérios que respeitem o caráter orgânico dos conjuntos documentais; ou seja, obedecendo ao princípio de respeito pelos fundos como norteador da sistemática do arranjo, nos quais estarão refletidos as origens e os processos que criaram os documentos.

Assim, Bellotto (1991, p.87) disserta que o arranjo consiste numa operação intelectual e material, pois significa "[...] organizar os documentos uns em relação com outros; as séries umas com as outras; os fundos, uns em relação aos outros; dar números de identificação aos documentos; colocá-los em caixas, pastas ou latas; ordená-los nas estantes". A operação intelectual do arranjo, segundo Bellotto (1991), consiste em operar, a partir da classificação 
dos fundos, os seguintes níveis: grupos (ou seção), série, conjunto lógico dentro da série e documento.

Corroborando com os apontamentos de Bellotto (1991), Tessitore (1989) define o arranjo:

[...] como a seqüência de operações que, com base no princípio da proveniência, e de acordo com um plano previamente estabelecido (cujo produto é o quadro de arranjo), visam a classificar os documentos de um arquivo de modo a que reflitam a estrutura administrativa e as funções exercidas pelas entidades produtoras. (TESSITORE, 1989, p.21).

Nota-se que, para essas autoras, a questão do arranjo documental em arquivos obedece ao princípio de proveniência e à questão da ordem original. A respeito do princípio de proveniência e da ordem original pressupõe-se que os conjuntos documentais devam se manter sempre agrupados respeitando a entidade que os gerou, implicando que os conjuntos e fundos documentais guardem ou mantenham os documentos, gerados ou recebidos, numa ação significativa e necessária para a manutenção do conjunto e seu contexto.

O princípio de proveniência e o caráter de organicidade servem como pilares para a concepção de arranjo documental nos arquivos, a partir do que podemos afirmar que arranjo documental arquivístico seja determinado por esses princípios.

Um outro conceito basilar para a Arquivística é o conceito de fundo. O fundo é uma emanação "natural" dos documentos, o qual possibilita que os conjuntos de documentos sejam arranjados estruturalmente, quando refletem um ordenamento interno da instituição ou entidade geradora da qual emanam; ou, sejam arranjados funcionalmente, quando as suas classificações não obedecem mais somente às estruturas da fonte emissora, mas às funções que o documento assumiu dentro da entidade geradora.

A primeira possibilidade apresenta-se como mais objetiva; nela o labor profissional segue o ordenamento dado pela fonte emissora de documentos. A segunda se apresenta como mais flexível, e talvez mais eficaz, uma vez que está mais voltada para quem procura a informação. Porém, o trabalho de ordenamento pressupõe um (des) arranjo, toda vez que os documentos nos fundos arquivísticos são arranjados pelos profissionais.

Todavia, existe uma classe de arquivos onde o arranjo baseado unicamente na proveniência ou organicidade não basta para a consecução da organização documental: são os chamados arquivos pessoais.

Os arquivos pessoais podem ser formados não unicamente por documentos produzidos ou emanados de uma única fonte, mas também constituídos por documentos, livros, fotografias e objetos não gerados, mas coletados, integrando então um conjunto de documentos que se configura como um arquivo pessoal.

Esta questão é de suma importância para a Arquivística. É um conceito que separa os arquivos das bibliotecas e museus, toda vez que as atividades destes últimos sejam as de coletar e colecionar, ou seja, uma atividade de acúmulo artificial, diferente da emissão supostamente natural da Arquivística.

Sendo a coleção um acúmulo documental artificial, seu arranjo obedeceria a outros critérios, não mais ligados somente à fonte geradora, mas também ao conteúdo do documento.

O critério primário num sistema de arranjo bibliográfico é o tema. Esse princípio alcançou sua unificação no final do século XIX e começo do século $X X$, quando foram inventados os sistemas de classificação universal.

Os esquemas que pretendiam ordenar o conhecimento do mundo produzido em todos os lugares e em todas as épocas refletiam uma visão de mundo baseada no conhecimento classificatório da ciência experimental do século XIX. Da mesma forma também, embora por diferentes caminhos e motivos, o princípio da proveniência e o caráter da organicidade derivam da biologia científica do século XIX.

Mas, assim como os arquivos pessoais, os conjuntos documentais fotográficos também recolocam de forma mais crítica e evidente a obsolescência dos princípios positivistas subjacentes nos sistemas de arranjo usados para a organização documental; como, por exemplo, a rigidez dos sistemas de classificação ou das normas de descrição.

\section{O ARRANJOCOMO NARRATIVA}

Num interessante e instigante artigo, Settis (2000) narra como Abby Warburg constrói sua 
biblioteca. Filho de um importante banqueiro alemão, Warburg troca sua herança pela possibilidade de poder comprar livros ao longo de toda a sua vida. Essa paixão pelos livros, na realidade, materialização do seu interesse por uma história da arte abrangente que considerasse e relacionasse outros aspectos da vida cultural, social e religiosa.

Warburg acreditava que a Renascença não era o único período da história que estabeleceu uma relação primordial com o antigo, outros momentos também o tinham feito; supunha a Antigüidade como uma constância dentro da história. Mas, se essa era a idéia que articulou sua obra e sua biblioteca, ele concebia seu ordenamento baseado nos problemas que a construção de sua hipótese acarretava. Por esse motivo, o constante aparecimento de problemas e a razão pela qual a biblioteca sofria constantes ordenamentos.

A produção intelectual de Warburg é relativamente pequena se comparada com a obra dos historiadores que posteriormente dirigiram o Instituto que ele criou. Porém, em última instância, a classificação inventada e reinventada múltiplas vezes por Warburg não se configura como uma metáfora nem como um reflexo da sua obra, mas a própria escrita da sua obra.

Embora Warburg conhecesse os sistemas de classificação vindos da Renascença ou os sistemas usados no seu tempo, nenhum deles se ajustava ao tipo de história que ele pretendia escrever. A historicidade de Warburg era uma história que estabelecia redes de significação entre diferentes atividades filosóficas, artísticas, científicas e culturais que ligavam a Antigüidade à Idade Média e Renascimento. Esse tipo de história abrangente e exaustiva era possível porque os livros necessários para ele estavam dispostos fisicamente, não de uma forma lógica ou matemática, mas numa forma de conexão entre áreas, momentos, culturas. O que significa que, aparentemente, a obra iria refletir a biblioteca; no fundo, a biblioteca foi a escrita/re-escrita de uma obra que não cessou de ser produzida ao longo da sua vida. O interesse de Warburg era tanto que ele acreditava que achar um livro desejado não era o mais importante, pois, talvez o livro ao lado pudesse conter mais e melhor informação; por esse motivo, estabelecer relações entre os livros era de suma importância.
Colocamos esse exemplo porque queremos destacar o ordenamento, não unicamente como um instrumento que possibilite a otimização da disponibilidade e recuperação da informação contida num acervo; mas para demonstrar que o arranjo, a classificação, a ordem de um acervo, constitui-se num ato comunicativo; como tal, deve ser "lido" e "ouvido" como se faz com uma mensagem narrativa e discursiva.

Assim, o exemplo de Warburg serve para percebermos que o arranjo é uma narrativa e que essa narrativa é estruturada por uma ordem que decorrentemente obedece a alguma finalidade específica. Porém, o exemplo evidencia uma narrativa na ordem dos livros. Ainda, existe uma escrita de uma obra pela simples correspondência espacial dos livros.

Afirmar então que o arranjo de livros é a escrita de uma obra vai além de uma metáfora. Embora obviamente não exista uma escrita gráfica sobre um suporte, ela é uma narrativa, um contar que vai além dos significados individuais de cada um dos textos para priorizar o sentido da narração, essa sim presente no arranjo ordenado com a finalidade de entender o passado medieval.

Esse exemplo serve para entender também o fundo José Pedro Miranda. Assim, numa biblioteca, cada livro nela contido constitui uma narração; porém, num estágio mais abrangente, quando vemos os livros arranjados numa biblioteca, essas narrações unitárias também podem dar lugar a uma narração maior. Esta última aparece graças ao arranjo, ou seja, a disposição do livro nas estantes, na prateleira. Estabelecendo uma sintaxe própria com os textos que se relacionam na biblioteca por proximidade ou por ausência.

No caso específico de fotografias em ambientes de arquivos, cada fotografia é também uma unidade significativa, mas diferente de um texto escrito; a fotografia é sintética, age com uma força centrípeta que articula um acontecimento, congelando-o numa imagem impressa num suporte.

Esta articulação sintética da fotografia faz com que o seu alcance, sua análise, sua interpretação ou a sua leitura seja feita de maneira diacrônica, numa espécie de verticalidade profunda. Eis o que acontece com a fotografia familiar, documentária, ou as fotografias em exposição em ambientes de bibliotecas ou museus. 
Já no caso da fotografia em ambientes de arquivo, ela possui um outro valor de análise, interpretação ou leitura. É o fato de ela formar sempre parte de um conjunto de fotografias; agregar um outro nível além do significado: o sentido. O sentido é possível de extrair a partir da disposição de várias fotografias que deslocam o significado, do verticalismo diacrônico para a horizontalidade sincrônica.

Essa sincronia permite várias possibilidades combinatórias, procurando revelar o significado e o sentido dos conjuntos fotográficos. No entanto esses significados e sentidos somente são possíveis pelo fato do arranjo ser também um ato de comunicação, o que quer dizer "contar alguma coisa": narrar algum acontecimento (MURGUIA, 2004).

José Pedro Miranda, como mencionamos anteriormente, foi um intelectual católico, vinculado à esfera pública de Ribeirão Preto. Como Warburg, ao longo de sua vida, José Pedro Miranda dedica-se a coletar, no caso, fotografias que contassem a vida de Ribeirão Preto.

A disposição que ele encontra para as fotografias é muito interessante; toda vez que, despreocupado com a naturalidade ou artificialidade com a qual chegam as fotografias até ele, preocupa-se em ordená-las segundo aquilo que ele quer contar sobre a cidade. E essa disposição das fotografias, executada por José Pedro Miranda, resulta num fenômeno de faces múltiplas:

1 - Por um lado, notamos uma intenção pragmática querendo fazer das fotografias um instrumento de escrita da obra, uma espécie de organização das ilustrações, ou de "citações visuais";

2 - Por outro lado, num ambiente de comunicação (arquivo), esse arranjo, essa disposição primariamente utilitária, torna-se uma narração, um contar a história de Ribeirão Preto. Não textual, nem verbal, mas visual;

3 - Porém, esse caráter de narração visual só existe porque alguém de fora percebeu essa dinâmica no acervo. Isso não quer dizer arbitrariedade aleatória, mas atribuição de sentido por parte do receptor, como em todo ato de comunicação.

\section{O N CLUS Ã O}

No contexto do Arquivo Público e Histórico de Ribeirão Preto, até o momento, a inteligibilidade, os sentidos e os significados dos documentos fotográficos do Fundo José Pedro Miranda, expressos no arranjo, são tributários exclusivos da instância acumuladora. O tratamento documental aplicado a estes documentos, somente sob a ótica da Arquivística, ou seja, segundo a proveniência e a organicidade, discorda das intenções e da construção narrativa de José Pedro Miranda.

As fotografias de José Pedro Miranda, tomadas enquanto documentos históricos, e enquanto conteúdos informacionais espelham uma narrativa construída por José Pedro Miranda, narrativa esta estruturante do arranjo.

Refletindo sobre a fotografia, deparamo-nos com o fato da fotografia ser um objeto de construção de representações, portanto, passível de re-significações criadas a partir do lugar que, posteriormente, ocupará no arranjo organizacional.

A ambigüidade presente na criação, na representação e na recepção fotográfica faz com que a fotografia ocasione uma peculiar complexidade no momento do seu tratamento documental, principalmente quando consideramos que os lugares aonde ela chegará se propõem a disponibilizar e disseminar uma informação objetiva. A tensão ocasionada pela ambigüidade/objetividade faz da fotografia um objeto desafiante.

A historiografia das últimas décadas revalorizou a imagem como fonte de pesquisa para a reconstrução do passado. Assim, perante a supervalorização do texto escrito como documento, afirmada pela historiografia positivista do século XIX, a Nova História, durante o século $X X$, colocou a fotografia como documento histórico, requerendo, para tanto, uma especificidade na formulação das perguntas, no momento da indagação sobre o passado, diferentes daquelas dirigidas ao texto escrito.

No entanto, a relação da fotografia com a história adquire outros contornos quando a fotografia é configurada como documento arquivístico. Diante da literatura arquivística e da experiência com os conjuntos de fotografias de José Pedro Miranda no Arquivo Público e Histórico de Ribeirão Preto, podemos constatar que a Arquivologia se relaciona com a fotografia sob a ótica basilar do princípio de proveniência, do caráter orgânico.

O fundo José Pedro Miranda caracteriza-se como um conjunto documental de fotografias que 
escapa aos princípios da ortodoxia arquivística. A sua localização, beirando a fronteira entre fundo e coleção, demonstra a necessidade de uma maior e mais aprofundada reflexão sobre os princípios arquivísticos utilizados para a consecução do tratamento documental. Mesmo porque o arquivo, tanto quanto a biblioteca e o museu são instituições históricas, isto é, foram configurando-se através do tempo até adquirirem as feições que atualmente possuem. Portanto, inscrever o arquivo na história, significa que ele pode estar aberto e engendrado a novas interpretações e a novas práticas. No caso, pensar historicamente o arquivo significa abrir a possibilidade de repensar o princípio de proveniência e o caráter da organicidade de forma a dialogar com a questão da coleção.

No tratamento documental elaborado para a organização dos documentos de José Pedro Miranda foi respeitado o ordenamento criado pelo próprio. Assim, as fotografias foram mantidas junto aos documentos escritos, seguindo o princípio da organicidade, consagrado pela Arquivística, caracterizando conjuntos documentais concebidos pelo titular para a construção da sua produção intelectual, isto é, no momento do arranjo, parte das fotografias foi mantida junto à documentação escrita, constituindo grupos, séries e dossiês, respeitando assim o princípio de proveniência e o caráter orgânico dos documentos que José Pedro Miranda produziu/acumulou ao longo de sua vida. Entretanto, as fotografias acumuladas por ele, e que não foram utilizadas para a consecução da sua produção intelectual, foram separadas e tratadas como coleção (ordenamento temático).

Esta separação deu lugar a uma "escrita" da vida e obra de José Pedro Miranda, que transcende aos seus textos e às obras publicadas. Como tal, a organicidade demonstra e evidencia a vida e a obra de José Pedro Miranda pela enunciação manifestada no ordenamento original.

\section{REFERÊNCIAS}

BARTHES, R. A câmara clara: nota sobre a fotografia. Rio de Janeiro: Nova Fronteira, 1984. 185p.

BELLOTTO, H.L. Arquivos permanentes: tratamento documental. São Paulo: T.A. Queiroz, 1991. 198p.

BENJAMIN, W. Pequena história da fotografia. In: BENJAMIN, W. Sobre arte, técnica, linguagem e política. Lisboa: Antropos, 1992. p.115-135.
Mas, como toda enunciação, ela também oculta. Neste caso, o tratamento documental imposto, que coloca parte das fotografias como coleção, silencia parte da vida e da obra de José Pedro Miranda.

Diante desta realidade, tem uma validade temerária a afirmação de que a organização, segundo os fundamentos da Arquivística, venha a refletir a vida do indivíduo. O tratamento documental, ao mesmo tempo em que é transparente, também é opaco. Tal como a memória, ele se sustenta na relação entre lembrança e esquecimento.

O que nos parece é que o problema fundo/ coleção somente poderá ser resolvido se o acervo de José Pedro Miranda for entendido como uma narrativa. A partir desta imagem, poderemos saber 0 que foi evidenciado e ocultado. E, mais uma vez, entender que todo este processo organizacional deve ser observado dentro da história.

Neste sentido, os problemas considerados como específicos e isolados, vindos principalmente da Arquivística e da Biblioteconomia, e também da Museologia (embora não seja esse o nosso tema de discussão), se colocados como manifestação de linguagem, quer dizer, como um fenômeno de comunicação, poderiam vir a ser esclarecidos.

Finalmente, especulamos que esses problemas emergentes possam vir a se configurar como objetos de discussão num território neutral, no qual questionamentos vindos de áreas diferentes possam dar lugar a uma nova episteme: a Ciência da Informação, uma Ciência da Informação aberta ao diálogo e não mais armada para os confrontos, cuja epistemologia, também histórica, possa ser enriquecida não somente a partir de respostas, mas de questionamentos baseados na reflexão e na prática da Arquivística, da Biblioteconomia e da Museologia.
CAMARGO, A.M.A; BELLOTTO, H.L. (Coord.). Dicionário de terminologia arquivística. São Paulo: Associação dos Arquivistas Brasileiros, 1996. 142p.

FREUND, G. La fotografia como documento social. Barcelona: Editorial Gustavo Gilli, 1976. 207p. (Colección Punto y Línea).

MIRANDA, J.P. A respeito do autor. Revista Focalizando Municípios, Ribeirão Preto, v. 1, n. 2, p.3, 1986. 
MIRANDA, J.P. Discurso proferido por José Pedro Miranda: solenidade de entrega do título de cidadão ribeirão-pretano. Ribeirão Preto: Câmara Municipal; Center Cópias Express, 1999. 8p.

MURGUIA, E.I. Historiografia e memória no filme Nós que aqui estamos por vos esperamos. Estudos de História, Faculdade de História, Direito e Serviço Social, Franca, v.11, n.2, p.85-102. 2004.

REGISTRO, T.C. O arranjo de fotografias em unidades de informação: fundamentos teóricos e aplicações práticas a partir do Fundo José Pedro Miranda do Arquivo Público e Histórico de Ribeirão Preto. 2005. 187f. Dissertação (Mestrado em Ciência da Informação) - Faculdade de Filosofia e Ciências, Universidade Estadual Paulista, Marília, 2005.
SAUSSURE, F. Curso de lingüística Geral. São Paulo: Cultrix, 1997.

SCHAEFFER, J.M. A imagem precária: sobre o dispositivo fotográfico. Campinas: Papirus, 1996.

SETTIS, S. Warburg continuatus: descrição de uma biblioteca. In: BARATIN, M.; JACOB, C. (Dir.). O poder das bibliotecas: a memória dos livros no Ocidente. Rio de Janeiro: UFRJ, 2000. p.108-154.

SONTAG, S. Ensaios sobre fotografia. Rio de Janeiro: Arbor, 1981. 199p.

TESSITORE, V. Arranjo: estrutura ou função? Arquivo: Boletim Histórico e Informativo, São Paulo, v.10, n.1, p.19-28, 1989. 